\title{
Comparison of Three Interbody Fusion Methods Through Posterior Approach for Lower Lumbar Spinal Tuberculosis in Adults: a Study of Mid- Long Term Follow-Up
}

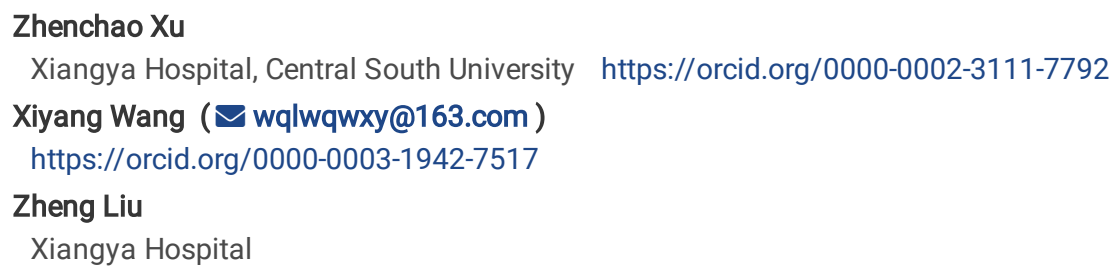




\section{Abstract}

Background: This study was conducted to compare mid-long term outcomes of three interbody fusion methods by way of posterior approach in adults with lower lumbar spinal tuberculosis.

Methods: A total of 126 lower lumbar spinal tuberculosis patients were treated by one-stage posterior debridement, interbody fusion, and instrumentation. Of the three types of interbody bone grafts, 41 patients (group A) were treated with autogenous bone graft for interbody fusion , 45 patients (group B) were treated with allogeneic bone grafting, and the remaining 40 (group C) patients were treated with titanium mesh cage. Clinical and radiographic data were gathered and analyzed.

Results: At the final follow-up, all patients were found to be completely cured. Neurological performance and quality of life were remarkably improved compared with those preoperative at the final follow-up. The preoperative lordosis angles of the three groups were significantly corrected compared with postoperative immediately values or those evaluated at the final follow-up. The correction loss of the group $C$ was lower than those of groups $A$ and B. All the patients obtained bone graft fusion; the fusion period of group B was longer than that of the other two groups. No significant differences among the three groups in adjacent segment degeneration rate were found at the last visit.

Conclusions: This mid-long term follow-up study established that one-stage posterior debridement, interbody fusion, and instrumentation can effectively treat lower lumbar spinal tuberculosis. Moreover, intervertebral titanium mesh cage bone graft may provide better outcomes than autogenous or allogeneic bone graft.

\section{Background}

Spinal tuberculosis (TB), the most common extrapulmonary TB, accounts for about $50 \%$ of bone and joint TB [1]. This severe spinal disease often causes spinal instability, kyphosis, spinal nerve dysfunction, or even paraplegia [2]. Lower lumbar spine (L3-L5) is known to be the stress focus and an influencing site of TB. It has the characteristics of refractory, high disability, and recurrence rate, which seriously influences the quality of patients' life. Anti-TB drugs are used across the entire treatment period; a reasonable surgical treatment improves the cure rate [3].

The optimal surgical approach for lower lumbar spinal TB in adults is still controversial $[4,5]$. As per the conventional surgical method, the anterior approach or combined posterior and anterior procedures have been preferred. Nevertheless, complex anatomical layers, enormous trauma, and increased complications were often linked to the surgical approaches. Based on literature reviews, posterior debridement, interbody fusion, and instrumentation can impart better clinical effect [6,7]. Often, TB of the spine annihilates the vertebral body as well as the intervertebral spaces and diminishes the stability. Reconstruction of the anterior and middle columns of the spine is advantageous in curing the lower lumbar spinal TB and to prevent recurrence. Although various kinds of bone graft material have been suggested $[8,9]$ for the interbody fusion of TB spondylitis, the treatment of lower lumbar spinal TB with allogeneic, autogenous, and/or titanium mesh cage bone grafts have not been reported. This study compares the efficacy of the three implant methods for treating lower lumbar spinal TB through posterior approach.

\section{Methods \\ Patient data}

The inclusion criteria for this study were as follows: (1) Lesions limited to one or two adjacent segments without extensive TB abscess were included (in case of multiple segments being involved, only one or two vertebral bodies needed to be addressed surgically); (2) Severe or progressive neurological impairment; (3) Spinal instability or deformity, progressive aggravation of the trend; (4) Low back pain persists and medications are ineffective.

The exclusion criteria included individuals who had undergone lower lumbar surgery; a history of congenital scoliosis, deformity or ankyloses; and multilevel large psoas abscess or gravity abscess. The included patients were followed up for at least 5 years with complete data.

A total of 126 lower lumbar spinal TB patients were treated with one-stage posterior debridement, interbody fusion, and instrumentation from January 2004 to December 2014. Of them, 75 were male and 51 female patients. The average age of the patients at surgery was $47.4 \pm 13.1$ years. The number of lesion segments treated in these individuals was one in 24, two in 94, and three in 8 cases Three types of interbody bone grafts were performed in this study: 41 patients underwent autogenous and intervertebral bone grafts to get the anterior and middle columns reconstructed (Group A); 45 patients were treated with allogeneic bone graft for reconstruction (Group B); and the rest of the 40 patients were treated with titanium mesh cage bone grafting (group C).

The clinical symptoms the individuals presented included lower-back pain, weakness, low fever, and varying degrees of lower limb dysfunction. The Erythrocyte sedimentation rate (ESR) and C-reactive protein (CRP) values were found to be raised to varying degrees. Preoperative diagnosis was conducted on the basis of serological examination and imaging outcomes, comprising spinal radiographic films, computed tomography (CT), and magnetic resonance imaging (MRI), which exhibited vertebral bone destruction, narrowing or disappearance of intervertebral spaces, and cold abscesses. The neurologic examination was conducted as per the Japanese Orthopedic Association (JOA) score. The Oswestry Disability Index (ODI) 
was utilized to assess the quality of life. Back pain and radicular pain of lower extremity were estimated with the help of Visual Analogue Scale (VAS). University of California at Los Angeles (UCLA) grading scale (Table 1) was applied to evaluate the adjacent segment degeneration (ASD) on radiograph.

Table 1

UCLA grading scale for degeneration of the disc

\begin{tabular}{|llll|}
\hline Grade & Narrow of disc space & osteophyte & Endplate sclerosis \\
\hline I & - & - & - \\
\hline II & + & - & - \\
\hline III & \pm & + & - \\
\hline & \pm & \pm & + \\
\hline The grade is based upon the most severe radiographic evident on plain radiographs \\
\hline
\end{tabular}

No significant differences among the three groups in the variables such as gender, age, diseased vertebrae number, preoperative ESR, CRP, JOA, ODI, VAS, and preoperative lordosis angles (Table 2) were found.

Table 2

Preoperative data of patients

\begin{tabular}{|llllll|}
\hline & Group A & Group B & Group C & Statistical value & $\mathrm{P}_{\mathrm{A}-\mathrm{B}} / \mathrm{P}_{\mathrm{A}-\mathrm{C}} / \mathrm{P}_{\mathrm{B}-\mathrm{C}}$ \\
\hline Gender (Male/Female) & $24 / 17$ & $27 / 18$ & $24 / 16$ & $\chi^{2}=0.025, P=0.988$ & $-/-/-$ \\
\hline Age (years) & $47.6 \pm 13.3$ & $45.6 \pm 13.6$ & $49.4 \pm 12.3$ & $\mathrm{~F}=0.905, P=0.407$ & $-/-/-$ \\
\hline Diseased vertebrae number & $1.9 \pm 0.5$ & $1.8 \pm 0.5$ & $1.9 \pm 0.5$ & $\mathrm{~F}=0.486, P=0.616$ & $-/-/-$ \\
\hline During of symptoms (months) & $3.0 \pm 1.2$ & $3.3 \pm 1.4$ & $3.6 \pm 1.5$ & $\mathrm{~F}=1.378, P=0.256$ & $-/-/-$ \\
\hline ESR (mm/h) & $68.4 \pm 18.3$ & $71.0 \pm 16.0$ & $69.9 \pm 19.7$. & $\mathrm{F}=0.223, P=0.800$ & $-/-/-$ \\
\hline CRP (mg/L) & $42.6 \pm 10.5$ & $46.8 \pm 16.2$ & $45.6 \pm 15.8$ & $\mathrm{~F}=0.968, P=0.383$ & $-/-/-$ \\
\hline JOA & $18.8 \pm 3.5$ & $18.2 \pm 3.8$ & $18.3 \pm 3.7$ & $\mathrm{~F}=0.279, P=0.757$ & $-/-/-$ \\
\hline ODI & $42.7 \pm 5.9$ & $43.6 \pm 6.1$ & $42.4 \pm 7.2$ & $\mathrm{~F}=0.387, P=0.680$ & $-/-/-$ \\
\hline VAS & $6.9 \pm 1.0$ & $7.1 \pm 1.1$ & $6.8 \pm 1.2$ & $\mathrm{~F}=0.620, P=0.540$ & $-/-/-$ \\
\hline Lordosis angle $\left(^{\circ}\right)$ & $16.1 \pm 4.5$ & $15.9 \pm 4.5$ & $16.3 \pm 5.2$ & $\mathrm{~F}=0.079, P=0.924$ & $-/-/-$ \\
\hline
\end{tabular}

\section{Preoperative management}

All patients were administered anti-TB drugs 2 to 4 weeks prior to the surgery, including isoniazid (300 mg/day), rifampicin (450 mg/day), and pyrazinamide (750 mg/day), and ethambutol (750 mg/day). They were strictly advised bed rest, strengthen their nutritional intake, and get anemia and hypoproteinemia corrected, simultaneously. Only when the symptoms of TB subside or disappear surgery may be conducted. During the anti-TB period, surgery may be performed in the presence of acute paralysis or progressive aggravation of neurological impairment, even if the ESR value does not decline.

\section{Surgical method}

The surgery was conducted with the patient lying in a prone position under general anesthesia.

Posterior midline incision was made considering the diseased vertebral body to be the center, in group $\mathrm{C}$, exposing bilateral lamina, facet joints, and transverse processes. Pedicle screws were fixed in one or two vertebrae adjacent to the affected vertebrae, and short pedicle screws were also installed in the affected vertebrae if the pedicle screw channel was not destroyed by infection. A hemilaminectomy or laminectomy was conducted on the highly damaged side of the lesion segment. Then, the diseased vertebral bodies were exposed by removing the superior and inferior articular processes and pedicle. With the help of curettes of different angles the lesion tissues including the sequestrum, necrotic intervertebral disc, caseous necrosis, and pus was removed, through the transpedicular space, until blood exuded on the bone surface. Thereafter the silicone tube was carefully placed deep into the lesion along the sinus tract, and the pus was absorbed under negative pressure. The procedure was repeated on the other side of the lesion if required. Installation of permanent rods and exerting compression with the help of cantilever bending maneuver under vision to correct the deformity and scoliosis. Both the upper and lower bone surfaces of the vertebral body were repaired as bone graft beds. One or two ideally shaped 
titanium mesh cages filled with autogenous bone particles (from healthy lamina and spinous process) were used on both sides and allogeneic bone particles in the middle on the basis of the shape and size of the bone graft bed to reconstruct the anterior middle column. Moreover, autogenous and allogeneic granular bones were implanted between bilateral transverse processes, or a suitable allogeneic bone plate was placed between vertebral lamina. Streptomycin powder $(1 \mathrm{~g})$ and isoniazid $(0.3 \mathrm{~g})$ were applied in the lesion area, and the incision was closed in layers on placing a drainage tube.

Trimmed autogenous iliac and allogeneic bone blocks were implanted in the bone graft bed in groups A and B, respectively. The rest of the surgical procedures were the same as followed in group $\mathrm{C}$.

Mycobacterium culture and histopathological examinations were carried out on the focus tissues of each patient during the operation.

\section{Postoperative management}

Routine antibiotics were administered and nutritional support provided post operation. The drainage tube was removed once the drainage volume collected in 24 hours was less than $30 \mathrm{ml}$. All the patients were continued to be administered with anti-TB drugs chemotherapy regimen post operation mentioned earlier for 12 to 18 months. Routine blood, liver function test, ESR and CRP evaluations were conducted to observe the adverse reactions and assess the efficacy of drugs. Following strict bed rest post operation for 4 weeks, patients were permitted to walk gradually with the help of an external brace for 6 months. Early rehabilitation training and physical therapy should be imparted to all patients to prevent thrombus and improve neurological function. Clinical and radiologic examinations were conducted once in every 3 months during the first year post operation in all patients and once in every 6 months thereafter.

\section{Evaluating standard and statistical analysis}

Operation period, intraoperative bleeding amount, and fusion period for each group of patients were documented. Bone healing was gauged as per the radiologic criteria of Lee et al through CT [10]. The following indexes were recorded preoperatively, postoperatively, and during the follow-up: (1) ESR and CRP; (2) neurological status according to JOA; (3) ODI and VAS; (4) lordosis angle; (5) ASD according to UCLA grading scale; and (5) surgeryrelated complications.

SPSS 20.0 software was used for performing statistical analysis. The measurement data of the three groups were compared by way of variance analysis first, followed by LSD $₫ t$ test to compare each group when the value of $P<0.05$. The numeration data were statistically analyzed with chisquare test. $P<0.05$ was considered statistically significant.

\section{Results}

\section{Clinical data}

The follow-up periods for the groups $A, B$, and $C$ were $75.4 \pm 11.8$ months, $76.5 \pm 11.2$ months, and $76.0 \pm 11.5$, respectively. All the patients diagnosed with lower lumbar spinal TB were tested to be clinically cured at the final follow-up.

The operation period and intraoperative blood loss were, respectively, recorded as $189.1 \pm 27.2 \mathrm{~min}$ and $946.3 \pm 185.2 \mathrm{ml}$ in group $\mathrm{A}, 161.8 \pm 24.6 \mathrm{~min}$ and $788.9 \pm 139.8 \mathrm{ml}$ in group B, $163.3 \pm 23.3 \mathrm{~min}$ and $777.5 \pm 130.6 \mathrm{ml}$ in group $\mathrm{C}$. The results indicated that the values of group A were greater than those of groups $\mathrm{B}$ and $\mathrm{C}(p<0.05)$. The ESR and CRP values normalized at 3 months post-surgery.

Patients suffering from preoperative neurological dysfunction exhibited improvement post-surgery in both groups. At the final follow-up, the JOA, ODI, and VAS values were recorded to be $27.1 \pm 1.8,9.9 \pm 1.5$, and $0.9 \pm 0.8$ in group $A ; 27.3 \pm 2.0,10.0 \pm 1.7$, and $0.9 \pm 0.7$ in group $B$; and $27.3 \pm 1.9,10.2 \pm$

1.7 , and $0.9 \pm 0.7$ in group C. Statistically significant differences were found between preoperative and the final follow-up values of JOA, ODI, and VAS $(p<0.05)$. Nevertheless, VAS values one day postoperatively was higher in group A than those of groups B and C. No significant differences in the values of JOA, ODI, and VAS were observed among the three groups at the final follow-up.

\section{Radiographic data}

The immediately recorded postoperatively and final follow-up lordosis angles were $29.8 \pm 4.3^{\circ}$ and $27.0 \pm 3.8^{\circ}$ in group $\mathrm{A}, 29.6 \pm 4.2^{\circ}$ and $26.8 \pm 4.6^{\circ}$ in group $B, 30.7 \pm 6.8^{\circ}$ and $30.0 \pm 6.6^{\circ}$ in group $C$, respectively. The correction loss values were $2.9 \pm 1.0^{\circ}, 3.1 \pm 0.8^{\circ}$, and $0.8 \pm 0.7$ in groups $A, B$, and $C$, respectively. The preoperative lordosis angles of the three groups were evaluated to be remarkably rectified compared with immediately recorded postoperatively or at the final follow-up. No significant differences were recorded in the correction rates among the three groups. Nevertheless, the correction loss of group C were observed to be lower than those of groups A and B.

The fusion periods of the groups $A, B$, and C, were $9.7 \pm 2.4$ months, $24.7 \pm 4.2$ months, and $9.5 \pm 2.7$ months, respectively, indicating group B's period to be longer than those of the other two groups (Table 3). During the final follow-up, 11 patients in group A had degeneration as per UCLA grading scale. The same was observed with 13 and 10 patients in group B and C. There were no statistically significant differences in rate of ASD among the three groups (Table 4). Imaging examination conducted at the final follow-up indicated that all the grafts were fused (Figs. 1-3). 
Table 3

Postoperative data of patients

\begin{tabular}{|c|c|c|c|c|c|}
\hline & Group A & Group B & Group C & Statistical value & $P_{A-B} / P_{A-C} / P_{B-C}$ \\
\hline Follow-up period (months) & $75.4 \pm 11.8$ & $76.5 \pm 11.2$ & $76.0 \pm 11.5$ & $\mathrm{~F}=0.111, P=0.895$ & $-/-/-$ \\
\hline Operation period (min) & $189.1 \pm 27.2$ & $161.8 \pm 24.6$ & $163.3 \pm 23.3$ & $\mathrm{~F}=15.572, P=0.000$ & $<0.05 /<0.05 />0.05$ \\
\hline Intraoperative blood loss (ml) & $946.3 \pm 185.2$ & $788.9 \pm 139.8$ & $777.5 \pm 130.6$ & $\mathrm{~F}=15.627, P=0.000$ & $<0.05 /<0.05 />0.05$ \\
\hline $\begin{array}{l}\text { ESR }(\mathrm{mm} / \mathrm{h}) \\
\text { 3-month postoperative } \\
\text { Final follow-up }\end{array}$ & $\begin{array}{l}11.5 \pm 3.0^{*} \\
4.2 \pm 1.5^{*}\end{array}$ & $\begin{array}{l}12.4 \pm 3.3^{*} \\
4.7 \pm 1.6^{*}\end{array}$ & $\begin{array}{l}11.9 \pm 2.8^{*} \\
4.5 \pm 1.8^{*}\end{array}$ & $\begin{array}{l}\mathrm{F}=0.883, P=0.416 \\
\mathrm{~F}=1.134, P=0.325\end{array}$ & $\begin{array}{l}-/-/- \\
-/-/-\end{array}$ \\
\hline $\begin{array}{l}\text { CRP (mg/L) } \\
\text { 3-month postoperative } \\
\text { Final follow-up }\end{array}$ & $\begin{array}{l}4.5 \pm 1.3^{*} \\
1.8 \pm 0.7^{\star}\end{array}$ & $\begin{array}{l}4.7 \pm 1.2^{*} \\
1.9 \pm 0.6^{*}\end{array}$ & $\begin{array}{l}4.6 \pm 1.2^{*} \\
1.9 \pm 0.9^{*}\end{array}$ & $\begin{array}{l}\mathrm{F}=0.259, P=0.772 \\
\mathrm{~F}=0.322, P=0.726\end{array}$ & $\begin{array}{l}-/-/- \\
-/-/-\end{array}$ \\
\hline $\begin{array}{l}\text { JOA } \\
\text { Final follow-up }\end{array}$ & $27.1 \pm 1.8^{*}$ & $27.3 \pm 2.0^{\star}$ & $27.3 \pm 1.9^{*}$ & $\mathrm{~F}=0.158, P=0.854$ & $-/-/-$ \\
\hline $\begin{array}{l}\text { ODI } \\
\text { Final follow-up }\end{array}$ & $9.9 \pm 1.5^{\star}$ & $10.0 \pm 1.7^{*}$ & $10.2 \pm 1.7^{\star}$ & $\mathrm{F}=0.389, P=0.679$ & $-/-/-$ \\
\hline $\begin{array}{l}\text { VAS } \\
\text { One day postoperative } \\
\text { Final follow-up } \\
\text { Lordosis angle }\left(^{\circ}\right) \\
\text { Postoperative immediately } \\
\text { Final follow-up } \\
\text { Correction rate }(\%) \\
\text { Correction loss }\left({ }^{\circ}\right) \\
\text { Fusion period (months) }\end{array}$ & $\begin{array}{l}8.5 \pm 0.9 \\
0.9 \pm 0.8^{*} \\
29.8 \pm 4.3^{\star} \\
27.0 \pm 3.8^{\star} \\
46.5 \pm 10.8 \\
2.9 \pm 1.0 \\
9.7 \pm 2.4\end{array}$ & $\begin{array}{l}6.0 \pm 1.1 \\
0.9 \pm 0.7^{\star} \\
29.6 \pm 4.2^{\star} \\
26.8 \pm 4.6^{*} \\
46.4 \pm 12.5 \\
3.1 \pm 0.8 \\
24.7 \pm 4.2\end{array}$ & $\begin{array}{l}5.9 \pm 1.0 \\
0.9 \pm 0.7^{\star} \\
30.7 \pm 6.8^{*} \\
30.0 \pm 6.6^{*} \\
47.5 \pm 7.6 \\
0.8 \pm 0.7 \\
9.5 \pm 2.7\end{array}$ & $\begin{array}{l}\mathrm{F}=85.732, P=0.000 \\
\mathrm{~F}=0.074, P=0.929 \\
\mathrm{~F}=0.501, P=0.606 \\
\mathrm{~F}=4.877, P=0.009 \\
\mathrm{~F}=0.138, P=0.872 \\
\mathrm{~F}=97.452, P=0.000 \\
\mathrm{~F}=312.363, P=0.000\end{array}$ & $\begin{array}{l}<0.05 /<0.05 />0.05 \\
-/-/- \\
-/-/- \\
>0.05 /<0.05 /<0.05 \\
-/-/- \\
>0.05 /<0.05 /<0.05 \\
<0.05 />0.05 /<0.05\end{array}$ \\
\hline
\end{tabular}

Table 4

Preoperative and postoperative UCLA grading scale in three groups

\begin{tabular}{|c|c|c|c|c|c|c|c|c|c|}
\hline \multirow[t]{2}{*}{ Grade } & \multicolumn{3}{|l|}{ Group A } & \multicolumn{3}{|l|}{ Group B } & \multicolumn{3}{|l|}{ Group C } \\
\hline & Preoperative & $\begin{array}{l}\text { Final } \\
\text { follow- } \\
\text { up }\end{array}$ & Degeneration $^{\Delta}$ & Preoperative & $\begin{array}{l}\text { Final } \\
\text { follow- } \\
\text { up }\end{array}$ & Degeneration $^{\Delta}$ & Preoperative & $\begin{array}{l}\text { Final } \\
\text { follow- } \\
\text { up }\end{array}$ & Degeneration $^{\Delta}$ \\
\hline I & 34 & 24 & 0 & 37 & 26 & 0 & 32 & 23 & 0 \\
\hline II & 7 & 16 & 10 & 8 & 17 & 11 & 8 & 16 & 9 \\
\hline III & 0 & 1 & 1 & 0 & 2 & 2 & 0 & 1 & 1 \\
\hline IV & 0 & 0 & 0 & 0 & 0 & 0 & 0 & 0 & 0 \\
\hline
\end{tabular}

\section{Complications}

Cerebrospinal fluid leakage was observed to occur in 2 cases in each of the three groups, which were cured after strengthen postoperative rehydration and delaying removal of drainage tube. 9 patients were detected with superficial wound infection and cured by antibiotics (four in group A, three in group B, and two in group C). 3 patients in group A complained of postoperative pain in the bone extraction area, which was overcome by administering nonsteroidal anti-inflammatory drugs. Catheter drainage through minimally invasive incision and regular chemotherapy were procedures through which local abscess recurrence experienced by 2 cases in group B were treated. Pseudarthrosis was experienced by 1 case in group $B$, for which he underwent anterior titanium mesh cage bone grafting.

\section{Discussion}

\section{Characteristics of lower lumbar spinal TB and its surgical treatment}

The lower lumbar spine is at the lowest position of the spine, at which region the body strength is concentrated, specifically at the junction of the active segment and the fixed end. The loading conditions are complex and easily cause force imbalance. The incidence of TB in the lower lumbar 
spine is insidious, and symptoms of some patients are atypical. Such individuals often suffer lower back pain, which is easily misdiagnosed as lumbar disc herniation, lumbar spinal stenosis, osteoporosis, or other degenerative diseases [11]. As the disease develops, Mycobacterium tuberculosis erodes the vertebral body to cause dead bones and abscesses, leading to instability or deformity of the spine, or invades the spinal canal causing neurological symptoms in lower limbs, even cauda equina syndrome. Therefore, solid bone graft fusion and favorable spinal stability are the prerequisites for curing lower lumbar spinal TB and the key to reduce spinal deformity.

The surgical treatment of spinal TB is specifically performed to remove the infection focus, relieve nerve compression, and reconstruct the stability of the spine $[12,13]$. Various surgical approaches were adopted to reduce lower lumbar spinal TB $[4,5,14]$. Majority of TB lesions involve the anterior and middle column; therefore, anterior debridement and bone grafting were recommended by some surgeons $[15,16]$. Nevertheless, the long term effect of the anterior approach showed that the bone graft was susceptible to collapse or absorption, and kyphosis was more severe [17, 18]. To overcome the shortcomings of this method some surgeons adopted anterior and posterior approaches for fixation and fusion, which enhanced the fusion rate of bone graft and the effect of kyphosis correction; however, this surgical procedure significantly increased iatrogenic trauma and hospitalization time, especially the elderly, children, and other physically weak patients [5].

\section{Advantages of posterior approach for lower lumbar spinal TB}

The posterior-only approach has turned out to be an effective treatment for lower lumbar spinal TB with the advent of posterior spinal instrumentation technology, as reported by several scholars [19-21]. Pedicle screws allow the fixation of the three columns of the spine, effectively restoring the normal physiological curvature of the spine, thus correcting kyphosis, and a better holding force can reduce the risk of loosening and fracture of the internal fixation, and results in a strong biological fixation in a short time post operation. Intervertebral and intertransverse or interlaminar bone grafting to achieve $360^{\circ}$ fusion can ensure long-term stability of the spine. The rationality of the posterior approach lies in the basic removal of the necrotic tissues and the ossified bone from around the lesion that prevents the entry of anti-TB drugs, thus destroying the positive environment essential for the survival of Mycobacterium tuberculosis. The rest of the small amount of lesion and abscesses can be absorbed by long-term, standardized anti-TB chemotherapy post-surgery [22]. As reported by Pang et al [23] the posterior approach was comparatively more effective in correcting kyphosis and less traumatic than the anterior approach. The outcomes of the single posterior and anterior posterior approaches in the treatment of lower lumbar spinal TB were compared by Xu et al [24], and the posterior procedure was found to be a better one with fewer complications.

\section{Three interbody fusion methods for anterior and middle column reconstruction}

As per the 3-columns theory of Denis [25], the long-term outcome of the posterior approach depends on the reconstruction of the anterior and middle columns through interbody fusion on removal of the TB debris. Autogenous bone was considered as the gold standard for bone grafting materials owing to good biocompatibility and absence of any disease transmission risk [26]. Nevertheless, autogenous bone transplantation cannot satisfy the need for interbody fusion due to complications in the donor site, and prolong the operation time and trauma. Moreover, the number of senile spinal TB patients increased, usually accompanied by osteoporosis and other systemic diseases, such as diabetes and cardiovascular disease, causing low osteoinductive activity and poor osteogenesis of the autogenous bone. The use of allogeneic bone decreases the related complications due to autogenous iliac bone, but lacks osteogenic induction ability. Theoretically, as a dead bone, allogeneic bone carries the risk of hiding Mycobacterium tuberculosis thus causing its recurrence. Furthermore, the bone block lacks blood circulation, thus hindering the supply of adequate anti-TB drug concentration locally. In this study, operation period and blood loss in group A were observed to be greater than those in groups B and C. Two patients of group B suffered local abscess recurrence, who were cured by minimally invasive surgery and regular chemotherapy. One patient in group B experienced pseudoarthrosis at the bone graft site, who was treated by revision surgery.

Of late, several scholars have evidenced titanium mesh cage bone graft carries the potential of reliable spine reconstruction, high fusion rate, effective sagittal imbalance maintenance, and low implant-related complications [27, 28]. Depending on the size and shape of the intervertebral bone defect, one or two suitable titanium mesh cage filled with autogenous bone particles from healthy lamina and spinous process were implanted. If the bone mass is inadequate, allogeneic bone particles can also be used for filling the middle of the cage. This intervertebral bone grafting technique has its unique advantages. Initially, the cage has sufficient support strength to achieve immediate stability, and is conveniently able to withstand compressive force to prevent it from fracture and displacement. Moreover, implantation of an ideally shaped titanium mesh cage can ensure a relatively large graft volume and bone contact surface between adjacent vertebral bodies, thus promoting graft fusion in an enhanced way. Eventually, intervertebral implanted titanium mesh can be shaped as per the specific shape of the bone defect, which can retain more healthy bone and prevent complications such as decreased stability of the spine and non-fusion of bone graft as a result of large bone defect. Certain scholars were concerned that the implantation of titanium mesh cage in the lesion area may likely lead to TB recurrence. Nevertheless, it has been demonstrated that TB bacilli have weak adhesion to titanium material and do not influence the bactericidal effect of anti-TB drugs [29]. In this study, all the patients belonging to group $C$ successfully attained bone fusion, while the fusion period was significantly less than that in group B and lower correction loss than those of groups $\mathrm{A}$ and $\mathrm{B}$.

Since the study encompasses a mid-long term follow-up of more than 5 years post-operation, it is assumed that ASD may occur over time. An earlier biomechanical study indicated that ASD was associated with loss of motor function in the fused segment, compensatory increase in adjacent segment mobility and mechanical stress, which resulted in augmenting load on the discs and articular processes [30]. Even though interbody fusion is the main cause of ASD, it can also restore the stability of the responsible segment. In this study, the rate of ASD was $26.8 \%$ in group A, $28.9 \%$ in group

Page 6/10 
B and $25.0 \%$ in group $C$ at the final visit. The findings were similar to the incidence of ASD (range 21.3-31.9\%) after lumbar fusion reported by recent meta-analysis [31].

\section{Conclusions}

Generally, this mid-long term follow-up study established that one-stage posterior debridement, interbody fusion, and instrumentation can effectively treat lower lumbar spinal TB. Moreover, intervertebral titanium mesh cage bone graft may result in better outcomes than autogenous or allogeneic bone grafts.

\section{Abbreviations}

ASD:Adjacent segment degeneration; CRP:C-reactive protein; CT:Computed tomography; MRI:Magnetic resonance imaging; ESR:Erythrocyte sedimentation rate; JOA:Japanese Orthopaedic Association; ODI:Oswestry Disability index; TB:Tuberculosis; UCLA:University of California at Los Angeles; VAS:Visual analogue scale.

\section{Declarations}

Ethics approval and consent to participate

This study protocol was approved by the Ethics Committee of Xiangya Hospital and the written informed consent was obtained from all patients. Each author certifies that all investigations were conducted in conformity with ethical principles.

Consent for publication

All patients signed informed consent forms to publish their personal details in this article.

Availability of data and materials

The datasets and materials generated or analyzed during the current study are available from the corresponding author on reasonable request.

Competing interests

The authors declare that they have no competing interests.

Funding

This work was supported by the National Natural Science Foundation of China (No.81672191). No benefit in any form has been or will be received from a commercial party related directly or indirectly to the subject of this manuscript.

Authors' contributions

Zhenchao Xu participated in the design of this study, performed statistical analysis, and drafted the manuscript. Zheng Liu collected the clinical data and follow-up details of the study and conducted the study. Xiyang Wang directed the study design and manuscript drafting. All authors read and approved the final manuscript.

Acknowledgements

Not applicable.

\section{References}

1. Jain AK, Kumar J. Tuberculosis of spine: neurological deficit. Eur Spine J. 2013;22(4):624-33.

2. Peto HM, Pratt RH, Harrington TA, LoBue PA, Armstrong LR. Epidemiology of extrapulmonary tuberculosis in the United States, 1993-2006. Clin Infect Dis. 2009;49(9):1350-57.

3. Rajasekaran S, Shanmugasundaram TK, Prabhakar R, Dheenadhayalan J, Shetty AP, Shetty DK. Tuberculous lesions of the lumbosacral region. A 15-year follow-up of patients treated by ambulant chemotherapy. Spine. 1998;23(10):1163-67.

4. Moon MS, Moon YW, Moon JL, Kim SS, Sun DH. Conservative treatment of tuberculosis of the lumbar and lumbosacral spine. Clin Orthop Relat Res. 2002;398:40-9.

5. Zeng H, Wang XY, Pang XY, Luo CK, Zhang PH, Wu P, Xu ZQ. Posterior only versus combined posterior and anterior approaches in surgical management of lumbosacral tuberculosis with paraspinal abscess in adult. Eur J Trauma Emerg S. 2014;40(5):607-16.

6. Liu Z, Zhang PH, Li WW, Xu ZC, Wang XY. Posterior-only vs. combined posterior-anterior approaches in treating lumbar and lumbosacral spinal tuberculosis: a retrospective study with minimum 7-year follow-up. J Orthop Surg Res. 2020;15(1):99.

7. Zhang HQ, Lin MZ, Li JS, Tang MX, Guo CF, Wu JH, Liu JY. One-stage posterior debridement, transforaminal lumbar interbody fusion and instrumentation in treatment of lumbar spinal tuberculosis: a retrospective case series. Arch Orthop Traum Su. 2013;133(3):333-41.

8. Govender S, Kumar KP. Cortical allografts in spinal tuberculosis. Int Orthop. 2003;27(4):244-8. 
9. Tosun B, Erdemir C, Yonga O, Selek O. Surgical treatment of thoracolumbar tuberculosis: A retrospective analysis of autogenous grafting versus expandable cages. Eur Spine J. 2014;23(11):2299-306.

10. Lee CK, Vessa P, Lee JK. Chronic disabling low back pain syndrome caused by internal disc derangements. The results of disc excision and posterior lumbar interbody fusion. Spine. 1995;20(3):356-61.

11. Mori T, Leung CC. Tuberculosis in the global aging population. Infect Dis Clin North Am. 2010;24(3):751-68.

12. Jain AK. Tuberculosis of the spine: a fresh look at an old disease. J Bone Joint Surg Br. 2010;92-B(7):905-13.

13. Wang XY, Pang XY, Wu P, Luo CK, Shen XJ. One-stage anterior debridement, bone grafting and posterior instrumentation vs. single posterior debridement, bone grafting, and instrumentation for the treatment of thoracic and lumbar spinal tuberculosis. Eur Spine J. 2014;23(3):830-7.

14. Jain AK, Dhammi IK, Prashad B, Sinha S, Mishra P. Simultaneous anterior decompression and posterior instrumentation of the tuberculous spine using an anterolateral extrapleural approach. J Bone Joint Surg Br. 2008;90(11):1477-81.

15. Zhao J, Lian XF, Hou TS, Ma H, Chen ZM. Anterior debridement and bone grafting of spinal tuberculosis with one-stage instrumentation anteriorly or posteriorly. Int Orthop. 2007;31(6):859-63.

16. Klockner C, Valencia R. Sagittal alignment after anterior debridement and fusion with or without additional posterior instrumentation in the treatment of pyogenic and tuberculous spondylodiscitis. Spine. 2003;28(10):1036-42.

17. Wang XY, Luo CK, Wu P, Ge L, Zhang HQ, Hu JZ. Single-stage transpedicular decompression, debridement, posterior instrumentation and fusion for thoracic tuberculosis with kyphosis and spinal cord compression in aged. Spine J. 2016;16(2):154-62.

18. Dai LY, Jiang LS, Wang W, Cui MZ. Single-stage anterior autogenous bone grafting and instrumentation in the surgical management of spinal tuberculosis. Spine. 2005;30(20):2342-49.

19. Zaveri GR, Mehta SS. Surgical treatment of lumbar tuberculous spondylodiscitis by transforaminal lumbar interbody fusion (TLIF) and posterior instrumentation. J Spinal Disord Tech. 2009;22(4):257-62.

20. Sundararaj GD, Behera S, Ravi V, Venkatesh K, Cherian VM, Lee V. Role of posterior stabilisation in the management of tuberculosis of the dorsal and lumbar spine. J Bone Joint Surg Br. 2003;85(1):100-6.

21. Kumar MN, Joseph B, Manur R. Isolated posterior instrumentation for selected cases of thoraco-lumbar spinal tuberculosis without anterior instrumentation and without anterior or posterior bone grafting. Eur Spine J. 2013;22(3):624-32.

22. Liu Z, Li WW, Xu ZC, Wang XY, Zeng H. One-stage posterior debridement, bone grafting fusion, and mono-segment vs. short-segment fixation for single-segment lumbar spinal tuberculosis: minimum 5-year follow-up outcomes. BMC Musculoskelet Disord. 2020;21(1):86.

23. Pang XY, Shen XJ, Wu P, Luo CK, Xu ZQ, Wang XY. Thoracolumbar spinal tuberculosis with psoas abscesses treated by one-stage posterior transforaminal lumbar debridement, interbody fusion, posterior instrumentation, and postural drainage. Arch Orthop Trauma Surg. 2013;133(6):765-72.

24. Xu ZQ, Wang XY, Shen XJ, Luo CK, Zeng H, Zhang PH, Peng W. Posterior only versus combined posterior and anterior approaches for lower lumbar tuberculous spondylitis with neurological deficits in the aged. Spinal Cord. 2015;53(6):482-7.

25. Denis F. The three column spine and its significance in the classification of acute thoracolumbar spinal injuries. Spine. 1983;8(8):817-31.

26. Przybylski GJ, Sharan AD. Single-stage autogenous bone grafting and internal fixation in the surgical management of pyogenic discitis and vertebral osteomyelitis. J Neurosurg. 2001;94(1):1-7.

27. Shen XJ, Liu HZ, Wang GP, Pang XY, Luo CK, Zeng H, Xu ZQ, Liu XY, Wang XY. The Role of Single-stage posterior debridement, interbody fusion with titanium mesh cages and short-segment instrumentation in thoracic and lumbar spinal tuberculosis. J Neurosurg Sci. 2017;61(5):473-80.

28. Yin XH, Liu ZK, He BR, Hao DJ. Single posterior surgical management for lumbosacral tuberculosis: titanium mesh versus iliac bone graft. Medicine. 2017;96(51):e9449.

29. Ha KY, Chung YG, Ryoo SJ. Adherence and biofilm formation of Staphylococcus epidermidis and Mycobacterium tuberculosis on various spinal implants. Spine. 2005;30(1):38-43.

30. Umehara S, Zindrick MR, Patwardhan AG, Havey RM, Vrbos LA, Knight GW, Miyano S, Kirincic M, Kaneda K, Lorenz MA. The biomechanical effect of postoperative hypolordosis in instrumented lumbar fusion on instrumented and adjacent spinal segments. Spine. 2000;25(13):1617-24.

31. Xia XP, Chen HL, Cheng HB. Prevalence of adjacent segment degeneration after spine surgery. Spine. 2013;38(7):597-608.

\section{Figures}

\section{Figure 1}

A 32-year-old female who demonstrated lesions received one-stage posterior debridement, autogenous bone interbody fusion, and instrumentation. $(a-c)$ Preoperative images showing TB of L3-L4 with the lordosis angle of $11^{\circ}$. (d-e) Postoperative X-ray demonstrating correction of the deformity and the lordosis angle was $32^{\circ}$. (f) CT showing satisfactory bone fusion at 9 months. ( $\mathrm{g}-\mathrm{h}$ ) X-ray displaying good internal fixation position and solid bone fusion, with correction loss of $3^{\circ}$ at the final visit. 

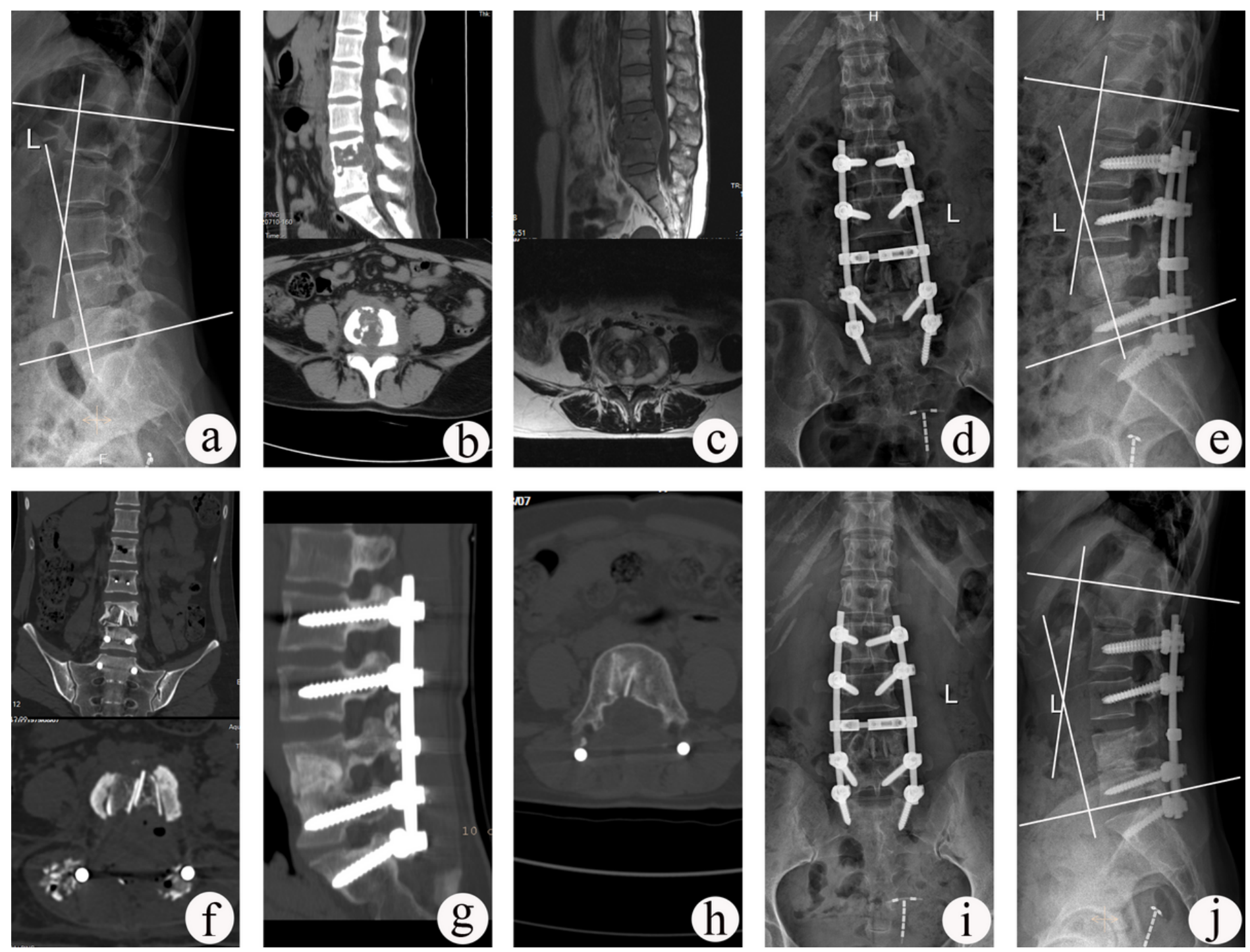

Figure 2

A 33-year-old female who demonstrating lesions received one-stage posterior debridement, allogeneic bone interbody fusion, and instrumentation. (ac) Preoperative images showing TB of L4-L5 with deformity (lordosis angle was $19^{\circ}$ ) and paravertebral abscess formation. (d-f) Postoperative X-ray demonstrating correction of the deformity (lordosis angle was $29^{\circ}$ ) and CT findings of allogeneic bone implanted into vertebral body. ( $\mathrm{g}-\mathrm{h}$ ) $\mathrm{CT}$ showing satisfactory bone fusion at 24 months. (i-j) X-ray displaying good internal fixation position and solid bone fusion, with the lordosis angle of $27^{\circ}$ at the 81 months' follow-up. 

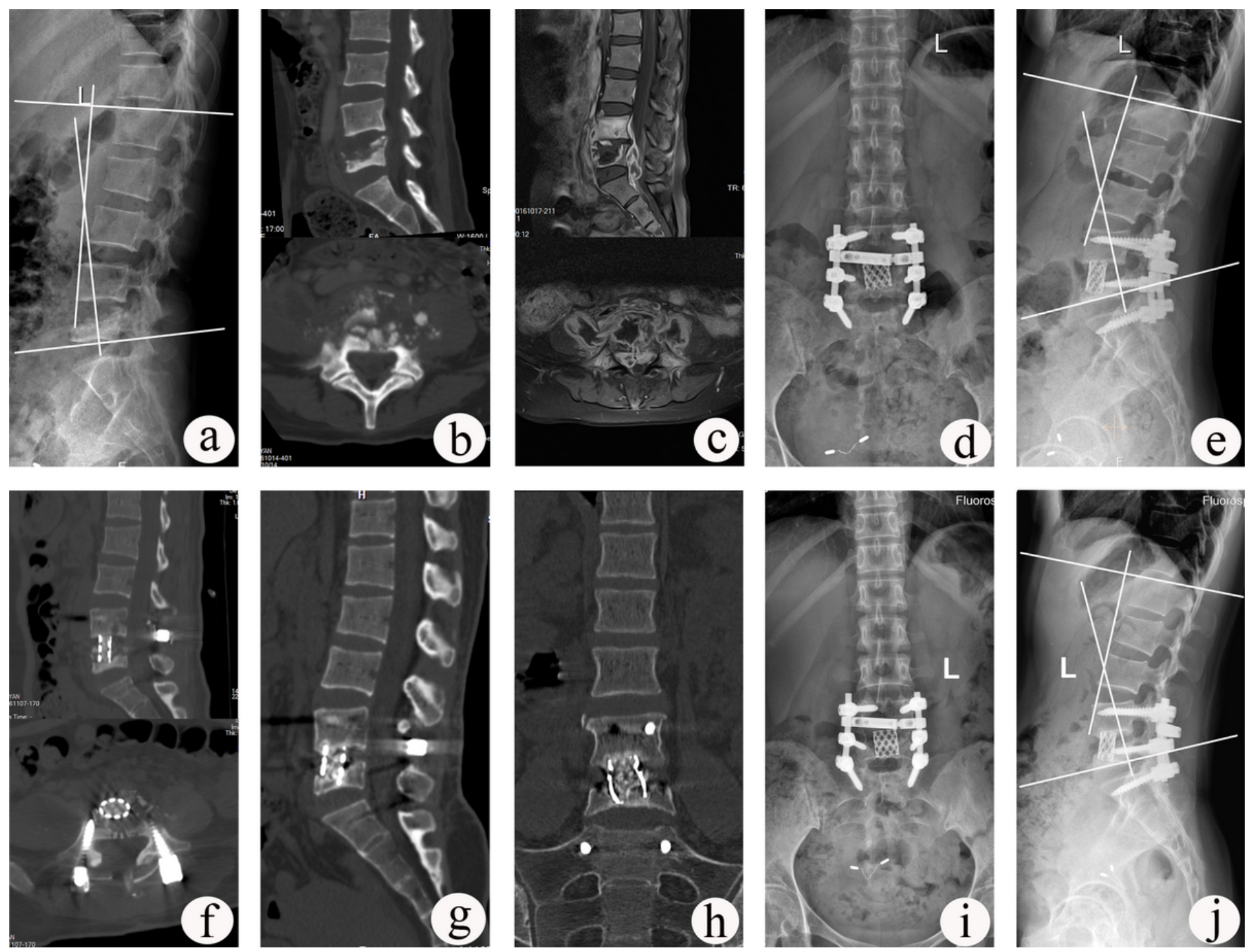

Figure 3

A 42-year-old male who demonstrated lesions received one-stage posterior debridement, one titanium mesh cage bone interbody fusion and instrumentation. $(\mathrm{a}-\mathrm{c})$. Preoperative images showing TB of L4-L5 with vertebral body collapse and paravertebral abscess formation; the lordosis angle was $13^{\circ}$. (d-f) Postoperative X-ray demonstrating good internal fixation position with the lordosis angle of $28^{\circ}$ and $C T$ findings of titanium mesh cage intervertebral bone graft. $(\mathrm{g}-\mathrm{h}) \mathrm{CT}$ showing satisfactory bone fusion at 9 months. (i-j) X-ray displaying solid bone fusion and no collapse or displacement of cage, with the correction loss of $1^{\circ}$ at the final follow-up. 